\title{
Fullerene Derivatives, Preparation, Identification and
}

\section{Use}

\author{
Eva Zemanova ${ }^{1}$, Karel Klouda ${ }^{1}$ and Eva Kostakova ${ }^{2}$ \\ 1. State Office for Nuclear Safety, Praha 1110 00, Czech Republic \\ 2. Technical University of Liberec, Liberec 460 01, Czech Republic
}

Received: March 01, 2013 / Accepted: April 06, 2013 / Published: June 25, 2013.

\begin{abstract}
This article is focused on oxidation and halogenation of fullerene, identification of the prepared products and their potential application. The Fourier transform infrared (FTIR) spectrometry was used for analysis of oxidized fullerene derivative and material balance and elemental analysis were used to identify the summary composition of the prepared fullerene halogen derivatives. We has conformed yet the radioprotective ability of oxidized fullerene in our recently published work radioprotective properties and toxicity test of $\mathrm{C}_{60}$ fullerene derivative in vivo \& in vitro. Since radioprotective properties are associated with the ability to recapture free radicals in the system (formed due to radiolysis of water in the physiological environment), this property is closely connected also with fire-retarder properties, when the fire is also a radical mechanism. We tested thermal properties of polyvinyl alcohol (hereinafter PVA) nanofibers prepared with $\mathrm{C}_{60}$ and its derivatives as nanocomposites. The TG-DTA and TG-DSC analysis were used for this purpose. We have demonstrated experimentally that a retarder on $\mathrm{C}_{60}$ oxi basis and $\mathrm{C}_{60}$ halogenderivative has good results in increasing of thermal resistance of PVA-based nanofibers.
\end{abstract}

Key words: $\mathrm{C}_{60}$ derivative, oxidation, halogenation, radioprotectivity, fire-retarder, nanofibres.

\section{Introduction}

Fullerenes are condensed polycyclic carbon substances with cage structure, with even numbers of carbon atoms arranged preferably into pentagons or hexagons. The most perfect spherical shape has the fullerene $\mathrm{C}_{60}$. Its surface is made up of 20 hexagons and 12 pentagons (similar to a classical sewn soccer ball). The pentagons are made of single covalent bonds and the hexagons are made up of a system of alternating single and double bonds.

The principal difference from graphite and diamond is the solubility of $\mathrm{C}_{60}$ in non-polar organic substances and its reactivity. Its typical reactions are associated with a transformation of arrangement from $\mathrm{sp}^{2}$ to $\mathrm{sp}^{3}$ and thus with a reduction of tension in the molecule. The $\mathrm{C}_{60}$ molecule is electropositive which means that

\footnotetext{
Corresponding author: Eva Zemanova, Ph.D., research field: $\quad \mathrm{C}_{60}$ fullerene derivatives. E-mail: Eva.Zemanova@sujb.cz.
}

it prefers nucleophilic or radical addition on a multiple bond. Fullerene $\mathrm{C}_{60}$ can be used for hydrogenation, alkylation, halogenation, oxidation, polymerization etc.

Substances identified as fire retarders are designed to slow down or stop the burning process, both by physical and chemical mechanisms.

The physical mechanism of fire retardation is based on endothermic decomposition of the retarder, flame cooling and dilution of combustible gases (e.g., $\mathrm{AlOH}_{3} \cdot x \mathrm{H}_{2} \mathrm{O}$ ).

The chemical mechanism is based on a substitution of radicals $\mathrm{H}^{*}$ and $\mathrm{OH}$.* with less reactive radicals or inert molecules produced by reactions with fire retarders. The exothermic reaction is slowed down and the temperature and production of combustion products decrease.

For polymer material, the treatment with a fire retarder may be applied on the polymer surface or "in 
bulk during the polymer processing; the retarders may be thus divided into those that do not react with the polymer (composites) and those that are integrated in the polymer chain.

Composites with at least one dimension in the nanometric area are identified as nanocomposites.

Apart from the fire-retarder properties, nanocomposites mostly also provide polymers prepared in this manner with additional desirable mechanical and physical properties. The most widespread nanoparticles used in industrial mass production are stratified nanoclays (stratified silicates, such as montmorillonite, kesterite, saponite). Synthesis of stratified nanoclays with polymer matrix, depending on the conditions and methods of preparation, enables to produce three main types of nanocomposites:

- phase separated;

- intercalated nanocomposites;

- exfoliated nanocomposites.

In intercalated nanocomposites polymer molecules permeate between the layers of silicate aggregates, they slightly expand but remain together, while in exfoliated nanocomposites, the individual layers are essentially dispersed in the individual matrix. This leads to optimization of mechanical properties, such as strength, elasticity, and to improvement of thermal stability (retardation). For phase-separated nanocomposites, the polymer matrix is unable to intercalate between clay layers so it only wraps them up. Clay particles in this case only perform the function of a microfilter.

Other investigated nanoparticles-based fire retarders were quartz flakes [1], metal oxides $\mathrm{TiO}_{2}, \mathrm{Fe}_{2} \mathrm{O}_{3}$ [2] and carbon-based nanoparticles. The latter included oxidized graphite, carbon singlewall nanotubes (SWNT), multiplewall nanotubes (MWNT) and carbon fibers. In most cases, an improved thermal stability of the polymers was found and a significant reduction of the rate of released heat $[3,4]$. The degree of dispersion of nanoparticles in the polymer is of essence [3].

In our earlier works $[5,6]$, we published a change of thermal stability of polyvinyl alcohol (hereinafter PVA) nanofibers after addition of $\mathrm{C}_{60} \mathrm{Oxi}$ which increased the thermal stability of nanofibers. In this work, we have focused on testing of thermal resistance of the nanofibers depending on the concentration of the added $\mathrm{C}_{60}$ oxi. The quantity of $\mathrm{C}_{60}$ oxi in relation to PVA before spinning was in the range $1-3 \mathrm{wt} . \%$.

\section{Materials and Methods}

\subsection{Preparation of Fullerene Derivatives}

The pristine fullerene $\mathrm{C}_{60}$ with $99.5 \%$ purity was obtained from SES Research, Houston, USA.

2.1.1 Fullerene Oxidation with Peracetic Acid

$500 \mathrm{mg}$ of $\mathrm{C}_{60}$ fullerene was mixed with $600 \mathrm{~mL}$ of $35 \%$ peracetic acid (Penta, Pharmaceutical division Prague). The mixture was constantly stirred at the laboratory temperature and a dark brown dispersion solution was obtained within half an hour which was heated and evaporated to ca. $100 \mathrm{~mL}$. The heating accelerated the process while the same result may be achieved after a longer period of time at the laboratory temperature when the peracetic acid evaporates spontaneously. After the acid was evaporated to 100 $\mathrm{mL}$, the clayey modified fullerene was settled with a centrifuge $(3,500 \mathrm{rev} / \mathrm{min}$, for $5 \mathrm{~min})$. By decanting the liquid portion, the peracetic acid, or its chemical residue, was removed. The solid part was repeatedly washed with small quantities of water, centrifuged again and the liquid portion was decanted. During washing with water always a certain part of the hydroxylated fullerene passed into the liquid portion, which was demonstrated by a light brown color of the acidic part. Decantation of that portion represents a certain weight loss of the product; however, the washing and repeated centrifugation was necessary and it was repeated at least three times. The achievement of neutral $\mathrm{pH}$ was a precondition for further use of the product in radioprotectivity biotests, 
as we published in Refs. [7, 8]. We tested preparation of $\mathrm{C}_{60}$ oxi for several years to always achieve reproducible results with optimum solubility in water so that it can be used as a radioprotective substance.

\subsubsection{Fullerene Bromination}

Fullerene $\mathrm{C}_{60}(4 \mathrm{~g})$ was added into liquid bromine $27.5 \mathrm{~mL}(85.3 \mathrm{~g})$ and the mixture was agitated at the laboratory temperature for $72 \mathrm{~h}$. Subsequently, the excessive bromine was removed by drying at $75^{\circ} \mathrm{C}$ for ca. $24 \mathrm{~h}$ until a constant weight was achieved. The product was $9.9 \mathrm{~g}$ of a green-brown substance. Based on the weight increase, the average composition was $\mathrm{C}_{60} \mathrm{Br}_{14}$ which has been confirmed by an elemental analysis of bromine.

\subsubsection{Chlorination of Bromofullerene}

The earlier prepared bromoderivative $\mathrm{C}_{60} \mathrm{Br}_{14}(5 \mathrm{~g})$ was added into $300 \mathrm{~mL}$ of tetra chloromethane. Subsequently, the mixture was percolated with gaseous chlorine of $99.8 \%$ purity released from a pressure cylinder. The reaction mixture was in contact for three days, the percolation with gaseous chlorine was performed with an interruption under slight reflux for $16.5 \mathrm{~h}$. Tetra chloromethane was replenished during the reaction time with additional $100 \mathrm{~mL}$. After evaporation of tetra chloromethane in a rotation evaporator the resulting red-brown powder was dried at $75{ }^{\circ} \mathrm{C}$ until a constant weight was achieved, while the total product was $4.65 \mathrm{~g}$. Based on a calculation and elemental analysis, the summary formula was determined as $\mathrm{C}_{60} \mathrm{Br}_{10} \mathrm{Cl}_{4}$.

\subsection{Identification of the Prepared Fullerene Derivatives}

Fourier transform infrared (FTIR) spectroscopy was used to identify fullerene oxoderivative. attenuated total reflection (ATR) analysis with FTIR spectrometry was performed on Brucker Sloha/FT-IR spectrometer, ATR crystal (Id. platinum Diamond 1 Refl), software OPUS 6.5, source IR SiC Globar. Measuring parameters are: number of spectrum scans 24 , resolution $4 \mathrm{~cm}^{-1}$, spectrum range $375-4,000 \mathrm{~cm}^{-1}$.

Material balance and elemental analysis were used to identify the summary composition of fullerene halogen derivatives. Subsequently ATR analysis with FTIR spectrometry (the same as above) was used.

2.3 Preparation of Nanofibres with $C_{60}$ and Its Derivatives as Nanocomposites

The nanofibers were prepared by electrospining (Department of Non-woven Textiles, Technical University Liberec).

The polyvinylalcohol (PVA, Mowiol 18-88, average mol wt. 130.000 from Kuraray) water solution 10 wt. $\%$ with crosslinking agents (4 wt. $\%$ of 40 wt. $\%$ glyoxal solution and $3 \mathrm{wt} . \%$ of 85 wt.\% phosphoric acid solution from dry PVA content) were electrospun and subsequently crosslinked at $135^{\circ} \mathrm{C}$ for $5 \mathrm{~min}$. The material was used as a control sample. Then PVA nanofibers with addition of 1 wt. $\%, 2$ wt.\% and 3 wt.\% of $\mathrm{C}_{60} \mathrm{Oxi}$ were produced. Used voltage for electrospinng was $20-25 \mathrm{kV}$. After electrospinning the same crosslinking process as for the control sample was used. Couptiss Ultra Sons HS30 with power $30 \mathrm{~W}$ and frequency $30 \mathrm{kHz}$ (Calemard, France) was applied for $60 \mathrm{~s}$ for dispersion of fullerenes inside the water. The final structure of electrospun nanofibers can be seen in Fig. 1.

The diameters of nanofibers measured by image analysis are: control sample $210 \pm 56 \mathrm{~nm}$; 1 wt.\% $\mathrm{C}_{60}$ oxi $214 \pm 73$ nm; 2 wt.\% $\mathrm{C}_{60}$ oxi $219 \pm 74 \mathrm{~nm} ; 3$ wt.\% C60oxi $224 \pm 72 \mathrm{~nm}$.

A change of thermal stability of the produced nanofibrous materials was assessed at Fire Rescue Service of Czech Republic, by means of TGA and TG-DSC method. Measurements of weight loss and relaxed-consumed thermal energy depending on used temperature and time are principles of these methods. The tests were performed according to accredited methods, apparatus STA 1500 THASS (mentioned in Table 1). The employed devices for TGA and DSC are provided in Table 1.

A similar method, including the subsequent analysis, was used to prepare nanofiber samples with added fullerene bromo- and bromochloroderivatives. Only an demonstrative electron microscope image of nanofibers 


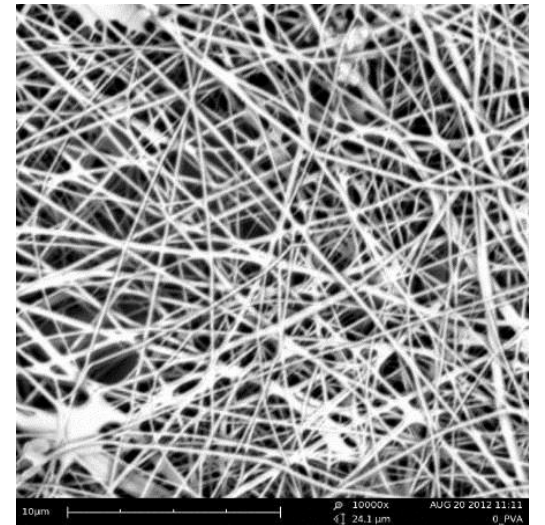

(a)

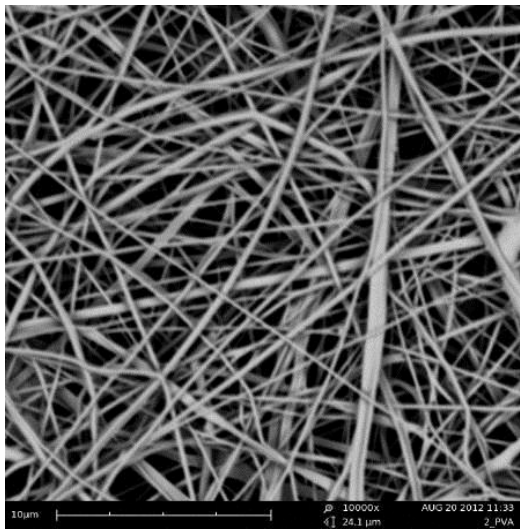

(b)

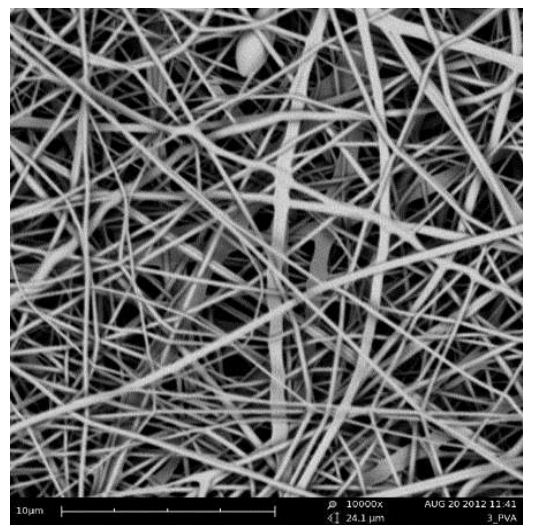

(c)

Fig. 1 Scanning electron images of control PVA naofibers (a) PVA with 2 wt.\%; (b) and with 3 wt.\%; (c) $\mathrm{C}_{60} 0 x i$ (magnification of all images is $10,000 \times$ ).

Table 1 Measuring instruments and devices.

\begin{tabular}{lll}
\hline Name of the measuring instrument/device & Measuring range & Calibration period (years) \\
\hline Barometer GPB 2300 & $(50-1,300) \mathrm{mbar}$ & 2 \\
Digital thermometer /humidity meter BONECO & $(-20$ to 50$){ }^{\circ} \mathrm{C},(20 \%$ to $100 \%)$ & 5 \\
Analytical scales SUMMIT, SI 234-A & $(0-230) \mathrm{g}$ & 2 \\
Ball flow meter & $(10-50) \mathrm{mL} / \mathrm{min}$ & 5 \\
STA i 1500 (Instrument Specialists Incorporated-THASS), & & \\
device for simultaneous TG-DTA and TG-DSC analysis & & \\
\hline
\end{tabular}

with fullerene bromochloro-derivative (3 wt.\%) is shown in Fig. 2.

\section{Results}

\subsection{Fullerene Oxidated with Peracetic Acid}

Obtained FTIR spectrum demonstrated presence of functional $-\mathrm{OH}$ and $-\mathrm{COOH}$ groups, Fig. 3.

The presence of the bands of valence vibrations of -OH groups of the fulleren oxoderivative is obvious at 3,379 and $3,198 \mathrm{~cm}^{-1}$, with -COOH groups at 1,770, $1,746,1,707$ and $1,636 \mathrm{~cm}^{-1}$ and $\mathrm{C}-\mathrm{O}$ groups at 1,034 $\mathrm{cm}^{-1}$.

TGA curves of samples No. 1 through No. 4 (Fig. 4 and Table 2) may be divided into several curves with different slopes, i.e., rate of weight reduction. The division with corresponding temperature ranges and corresponding weight reductions is provided in Table 2. Table 3 indicates parameters of the detected thermal processes on the DSC curve. The thermal energy changes $(\Delta \mathrm{H})$ were determined as areas of the individual peaks that represent the respective thermal

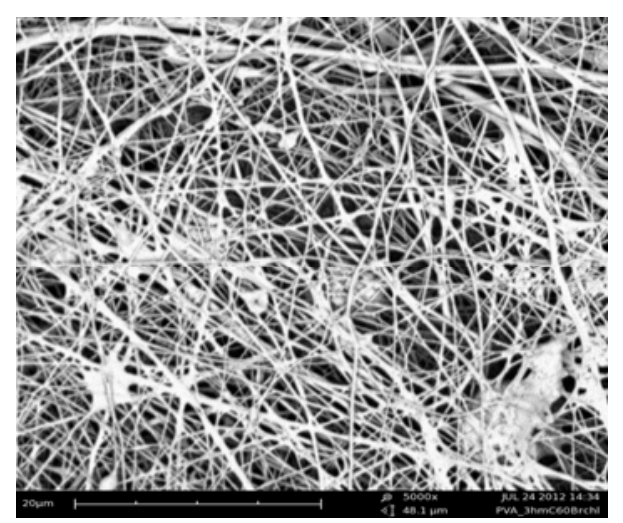

Fig. 2 Scanning electron images of PVA nanofibers with 3 wt.\% bromochlorofullerene composite (magnification of image is $10.000 \times$ ).

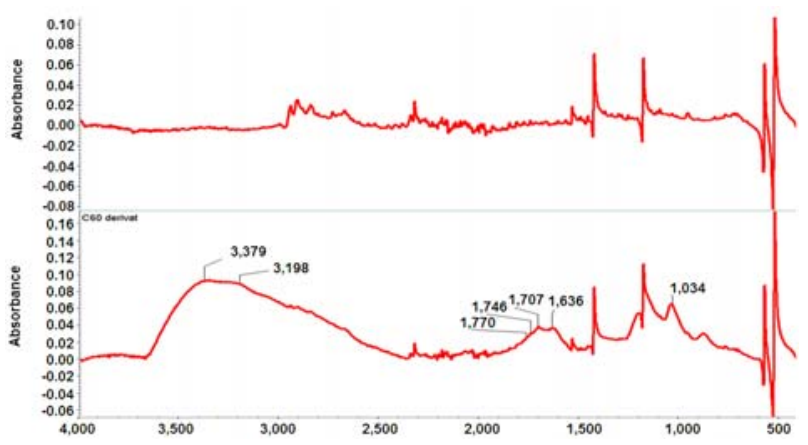

Fig. 3 IR spectrum of the pristine fullerene $C_{60}$ (upper curve) and its oxoderivative (lower curve). 


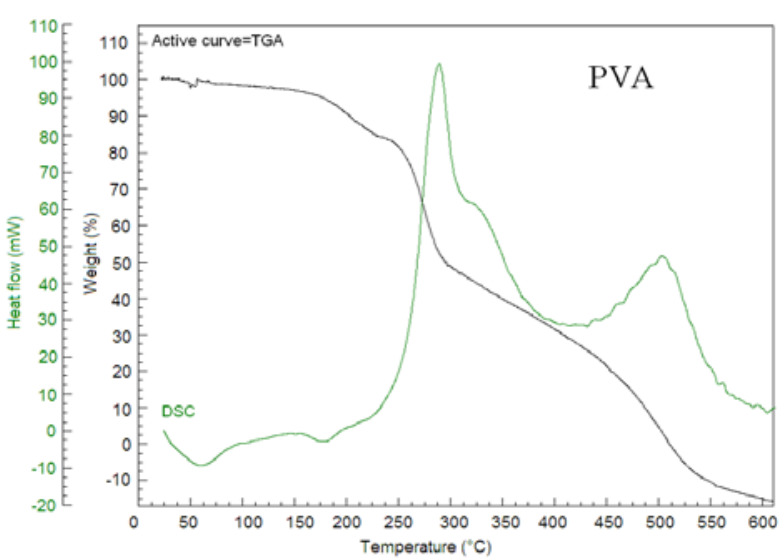

(a)

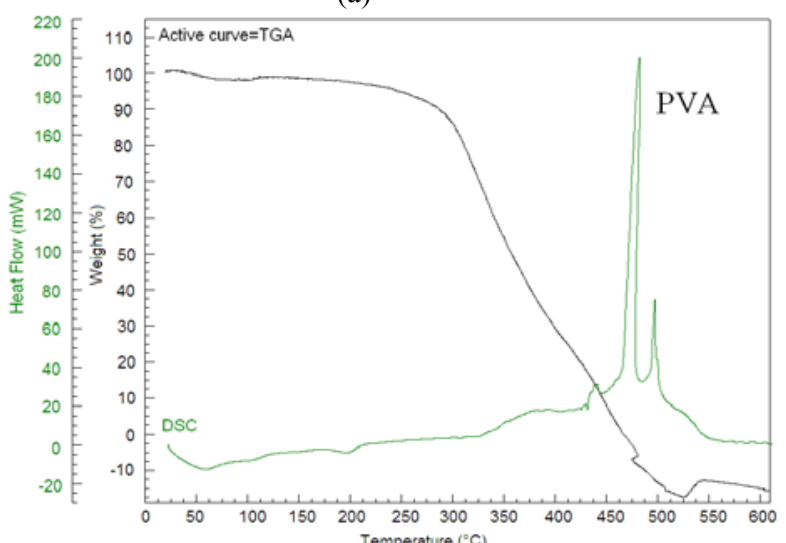

(c)

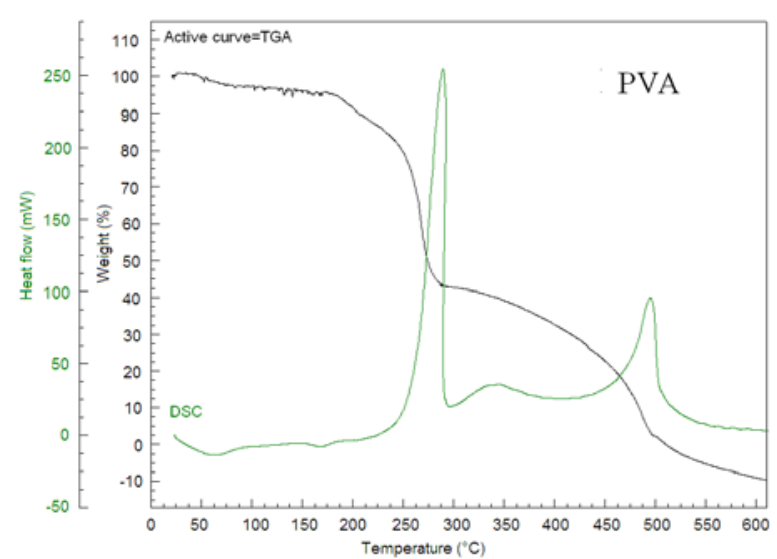

(b)

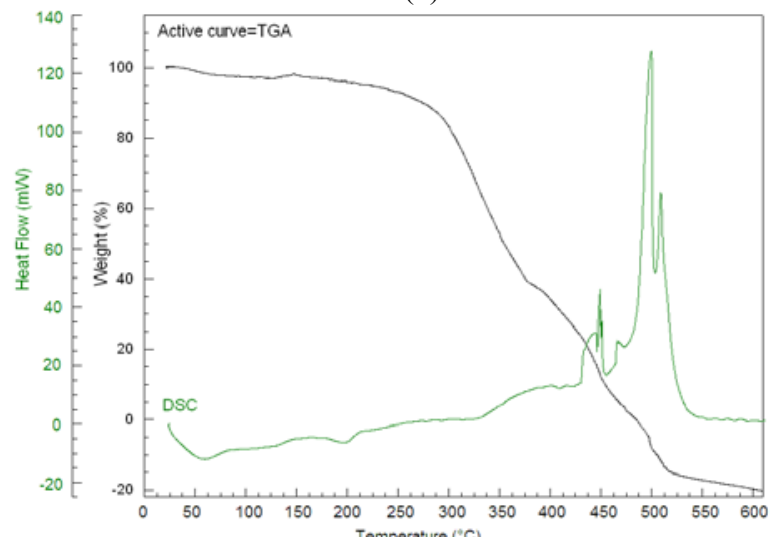

(d)

Fig. 4 Thermal analysis of PVA nanofibers without composite and with $\mathrm{C}_{60}$ oxi composite in the order: (a) PVA, blank; (b) PVA, 1 wt.\% of C60oxi; (c)PVA, 2 wt.\% of C60oxi; (d) PVA, 3 wt.\% of C60oxi; degradation medium, air, air flow rate 20 $\mathrm{mL} / \mathrm{min}$, temperature regime $25-600{ }^{\circ} \mathrm{C}$, heating rate $10^{\circ} \mathrm{C} / \mathrm{min}$, weighted quantity $6.4 \mathrm{mg}$.

Table 2 Division of the TGA curve into temperature intervals.

\begin{tabular}{|c|c|c|c|}
\hline Sample No. & Interval No. & Temperature range $\left({ }^{\circ} \mathrm{C}\right)$ & Weight loss (\%) \\
\hline \multirow{3}{*}{1} & 1 & $25.0-176.5$ & 4.9 \\
\hline & 2 & $176.5-235.2$ & 11.2 \\
\hline & 3 & $235.2-294.8$ & 34.2 \\
\hline \multirow[t]{3}{*}{ PVA-blank } & 4 & $294.8-469.3$ & 33.3 \\
\hline & 5 & $469.3-532.4$ & 23.4 \\
\hline & 1 & $25.0-81.4$ & 5.2 \\
\hline \multirow{2}{*}{2} & 2 & 81.4-202.9 & 4.3 \\
\hline & 3 & $202.9-241.8$ & 7.5 \\
\hline \multirow{3}{*}{ PVA- $1 \% \mathrm{C}_{60} \mathrm{Oxi}$} & 4 & $241.8-287.2$ & 39.3 \\
\hline & 5 & $287.2-453.3$ & 21.2 \\
\hline & 6 & $453.3-498.1$ & 19.3 \\
\hline \multirow{2}{*}{3} & 1 & $25.0-293.8$ & 11.9 \\
\hline & 2 & $293.8-385.0$ & 52.8 \\
\hline \multirow{2}{*}{ PVA- $2 \% \mathrm{C}_{60} \mathrm{oxi}$} & 3 & $385.0-437.5$ & 20.9 \\
\hline & 4 & $437.5-545.7$ & 27.3 \\
\hline \multirow{2}{*}{4} & 1 & $25.0-288.9$ & 12.9 \\
\hline & 2 & 288.9-377.0 & 47.6 \\
\hline \multirow{2}{*}{ PVA- $3 \% \mathrm{C}_{60} \mathrm{oxi}$} & 3 & $377.0-450.1$ & 27.7 \\
\hline & 4 & $450.1-512.2$ & 25.0 \\
\hline
\end{tabular}


Table 3 Parameters of the ongoing thermal processes (DSC) for nanofibers PVA without and with C60oxi addition.

\begin{tabular}{|c|c|c|c|c|c|}
\hline $\begin{array}{l}\text { Sample } \\
\text { No. }\end{array}$ & $\begin{array}{l}\text { Thermal } \\
\text { process No. }\end{array}$ & $\begin{array}{l}\text { Temperature range } \\
\left({ }^{\circ} \mathrm{C}\right)\end{array}$ & $\begin{array}{l}\Delta H \\
(\mathrm{~kJ} / \mathrm{kg})\end{array}$ & $\begin{array}{l}H_{n} \\
(\mathrm{~mW})\end{array}$ & $\begin{array}{l}\text { Overall thermal energy } \\
\text { change } \Delta H(\mathrm{~kJ} / \mathrm{kg})\end{array}$ \\
\hline \multirow{2}{*}{1} & 1 & $25.0-95.5$ & -457.8 & 6.0 & \multirow{4}{*}{$5,040.4$} \\
\hline & 2 & $154.1-195.7$ & -56.6 & 2.1 & \\
\hline \multirow{2}{*}{ PVA-blank } & 3 & $220.4-389.1$ & $4,176.4$ & 95.8 & \\
\hline & 4 & $441.6-565.5$ & $1,378.4$ & 17.3 & \\
\hline \multirow{2}{*}{2} & 1 & $25.0-89.2$ & -508.2 & 5.2 & \multirow{5}{*}{$4,458.6$} \\
\hline & 2 & $146.1-180.8$ & -38.2 & 4.2 & \\
\hline \multirow{3}{*}{$\begin{array}{l}\text { PVA } 1 \% \\
\mathrm{C}_{60} \mathrm{Oxi}\end{array}$} & 3 & $234.7-293.6$ & $3,042.1$ & 248.7 & \\
\hline & 4 & $295.2-377.7$ & 368.0 & 14.5 & \\
\hline & 5 & $438.9-520.5$ & $1,594.9$ & 65.9 & \\
\hline \multirow{2}{*}{3} & 1 & $25.0-83.1$ & -426.6 & 3.6 & \multirow{5}{*}{916.6} \\
\hline & 2 & $178.0-215.4$ & -41.0 & 1.5 & \\
\hline \multirow{3}{*}{$\begin{array}{l}\text { PVA } 2 \% \\
\mathrm{C}_{60} \mathrm{Oxi}\end{array}$} & 3 & $428.1-442.4$ & 41.5 & 10.6 & \\
\hline & 4 & $451.8-483.1$ & $1,156.3$ & 168.0 & \\
\hline & 5 & $483.1-503.7$ & 186.4 & 37.2 & \\
\hline \multirow{2}{*}{4} & 1 & $25.0-81.4$ & -418.8 & 3.0 & \multirow{5}{*}{$2,000.3$} \\
\hline & 2 & $174.5-210.9$ & -43.9 & 2.2 & \\
\hline \multirow{3}{*}{$\begin{array}{l}\text { PVA } 3 \% \\
\mathrm{C}_{60} \mathrm{Oxi}\end{array}$} & 3 & $426.3-453.1$ & 243.5 & 32.1 & \\
\hline & 4 & $453.1-501.9$ & $1,454.2$ & 109.1 & \\
\hline & 5 & $501.9-538.2$ & 765.3 & 75.7 & \\
\hline
\end{tabular}

$\Delta H$ : Thermal energy change based on DSC curves $(\Delta H>0$ : exothermic process, $\Delta H<0$ : endothermic proces);

$H_{n}$ : Peak height of a thermal process on a DSC curve in the absolute value related to the point representing the beginning of the thermal process.

process, i.e., the area outlined with the DSC curve and a line between points that indicate the beginning and the end of the thermal process. The peak area is directly proportional to the heat released or consumed during the reaction and the peak height $\left(H_{n}\right)$ is directly proportional to the reaction rate.

From $25^{\circ} \mathrm{C}$ (i.e., from the beginning of the analysis) all samples demonstrated an endothermic process with the peak area on the DSC curve up to $510 \mathrm{~kJ} / \mathrm{kg}$. It probably represents evaporation of moisture. Then, at 145-180 ${ }^{\circ} \mathrm{C}$, another endothermic process occurred with the peak area on the DSC curve up to $60 \mathrm{~kJ} / \mathrm{kg}$. All samples demonstrated a very distinct exothermic process with the peak area on the DSC curve above $1,000 \mathrm{~kJ} / \mathrm{kg}$. In samples No. 1 and 2 this exothermic process started as early as at $220.4{ }^{\circ} \mathrm{C}$ (sample No. 1) and $234.7{ }^{\circ} \mathrm{C}$ (sample No. 2) and the peak area on the DSC curve was $4,176.4 \mathrm{~kJ} / \mathrm{kg}$ (sample No. 1) and $3,042.1 \mathrm{~kJ} / \mathrm{kg}$ (sample No. 2). In samples No. 3 and No. 4 the distinct exothermic process started only at around $450{ }^{\circ} \mathrm{C}$ and the peak area on the DSC curve did not exceed 1,500 kJ/kg. In samples No. 1 and No. 2 there were two very noticeable exothermic processes, while in samples No. 3 and No. 4 there was only one, as described above.

The thermal analysis of Fig. 4 and values of the total $\Delta H$ (Table 3 ) indicate that the thermal resistance of nanofibers containing $3 \%$ of $\mathrm{C}_{60}$ oxi deteriorated in comparison with nanofibers with $2 \%$. A rapid decrease of thermal resistance occurred in samples containing $4 \%$ and $5 \%$ of $\mathrm{C}_{60}$ oxi. The total thermal energy change accompanying decomposition of the prepared nanofibers exceeded even the value of "clean" (non-composite) PVA nanofibers. Addition of $4 \%$ and $5 \%$ of $\mathrm{C}_{60}$ oxi causes thermal instability of the nanofibers.

\subsection{Fullerene Halogenated with Bromine and Chlorine}

The result of interpretation of the IR spectrum of the bromo- and bromochloroderivative might be that the substances are the same, see the measured 
spectrums in Fig. 5 and Fig. 6. Maximum vibrations at $844 \mathrm{~cm}^{-3}$ and $773 \mathrm{~cm}^{-3}$ corresponds to the halogen presence. However, the TGA and DSC analyses have demonstrated different behavior of the substances during thermal stress, see the TGA and DSC curves in Fig. 7 and Fig. 8.

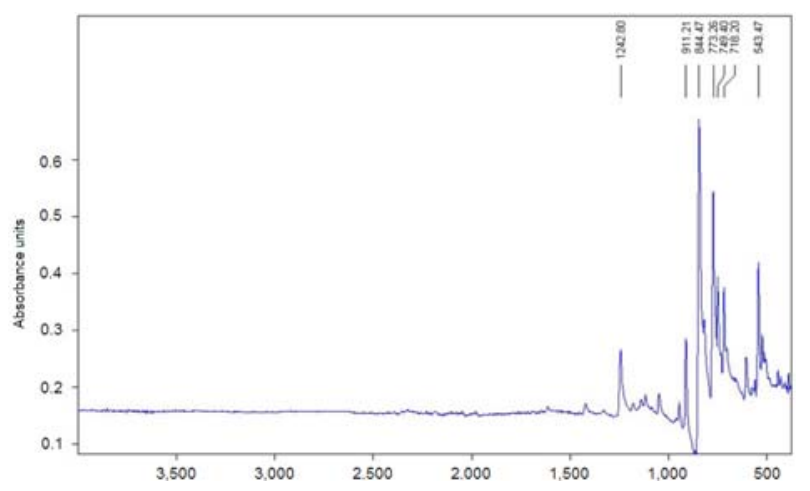

Fig. 5 IR spectrum of fullerene bromoderivative.

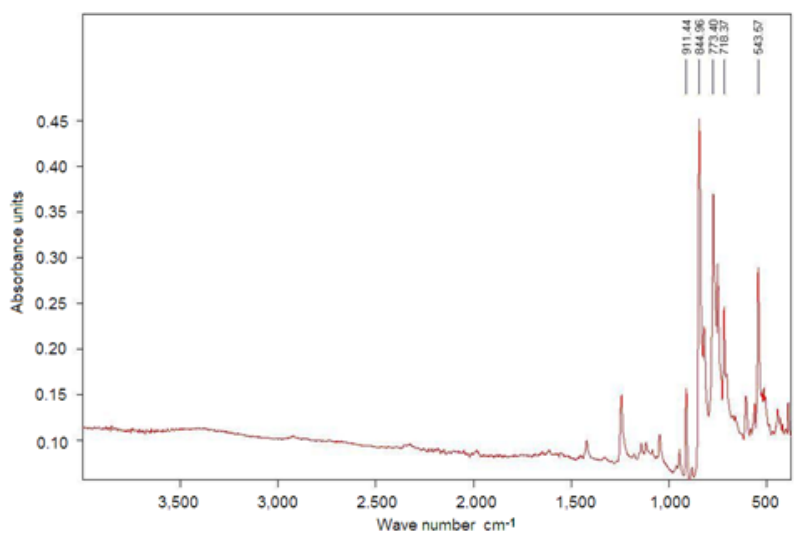

Fig. 6 IR spectrum of fullerene bromochloroderivative.

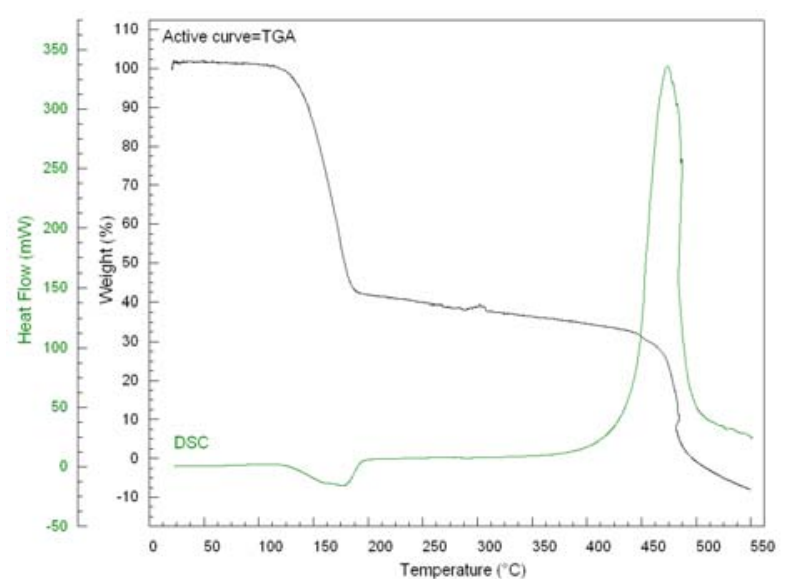

Fig. 7 Thermal analysis of fullerene bromoderivative (degradation medium is air, air flow rate $20 \mathrm{~mL} / \mathrm{min}$, temperature regime $25-550{ }^{\circ} \mathrm{C}$, heating rate $10{ }^{\circ} \mathrm{C} / \mathrm{min}$, weighted quantity $12.3 \mathrm{mg}$ ).
Both the substances first demonstrated an end effect with the highest weight loss for $\mathrm{C}_{60} \mathrm{Br}_{14}$ (Table 4) which started at $126{ }^{\circ} \mathrm{C}$; for $\mathrm{C}_{60} \mathrm{Br}_{10} \mathrm{Cl}_{4}$ it was at a higher temperature, specifically at $152{ }^{\circ} \mathrm{C}$. A significant exothermic process occurred for bromochloroderivative at $390{ }^{\circ} \mathrm{C}$ and for bromoderivative at $418{ }^{\circ} \mathrm{C}$, with the peak area on the DSC curve, which corresponds to $2,084 \mathrm{~kJ} / \mathrm{kg}$ for bromochloroderivative and to $4,233 \mathrm{~kJ} / \mathrm{kg}$ for bromoderivative. At temperatures over above $450{ }^{\circ} \mathrm{C}$ bromochloroderivative demonstrated two more exothermic processes (Table 5 and Fig. 8).

The sum of the $\Delta \mathrm{H}$ value of the overall thermal process of both the substances has shown that the exothermic process of bromoderivative $(3,906 \mathrm{~kJ} / \mathrm{kg})$ is practically double of that of bromochloroderivative $(2,270 \mathrm{~kJ} / \mathrm{kg})$.

For further specification of differences between the two substances, we heated both the samples, under identical condition as during their TGA and DSC measurements, to $250{ }^{\circ} \mathrm{C}$, and the samples were subsequently subject to IR analysis. The resulting spectrums after the heating are provided in Figs. 9 and 10. Comparisons of IR spectrums of both the derivatives before and after the heating are shown in Figs. 11-13 compares IR spectrums of products generated after heating of the derivatives to $250{ }^{\circ} \mathrm{C}$.

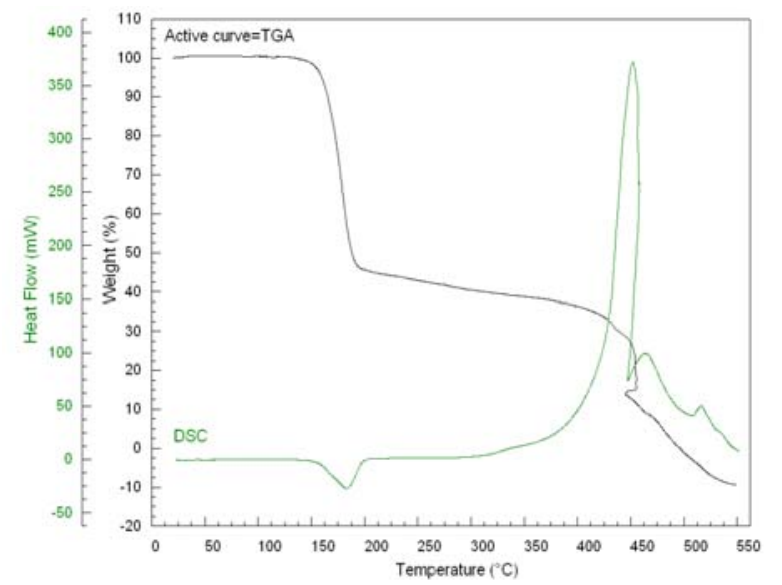

Fig. 8 Thermal analysis of fullerene bromochloroderivative (degradation medium is air, air flow rate $20 \mathrm{~mL} / \mathrm{min}$, temperature regime $25-550{ }^{\circ} \mathrm{C}$, heating rate $10^{\circ} \mathrm{C} / \mathrm{min}$, weighted quantity $10.4 \mathrm{mg}$ ). 
Table 4 Division of the TGA curve into temperature intervals for fullerene bromo- and bromochloroderivative.

\begin{tabular}{llcc}
\hline Sample & Interval No. & Temperature range $\left.{ }^{\circ} \mathrm{C}\right)$ & Weight loss $(\%)$ \\
\hline \multirow{2}{*}{$\mathrm{C}_{60} \mathrm{Br}_{14}$} & 1 & $25.0-126.8$ & 1.0 \\
bromoderivative & 2 & $126.8-188.3$ & 56.1 \\
& 3 & $188.3-445.2$ & 10.5 \\
& 4 & $445.2-495.6$ & 32.0 \\
\hline & 1 & $25.0-152.0$ & 1.8 \\
$\mathrm{C}_{60} \mathrm{Br}_{10} \mathrm{Cl}_{4}$ & 2 & $152.0-191.9$ & 51.2 \\
bromochloroderivative & 3 & $191.9-435.7$ & 16.5 \\
& 4 & $435.7-466.6$ & 21.9 \\
& 5 & $466.6-527.9$ & 15.8 \\
\hline
\end{tabular}

Table 5 Parameters of ongoing thermal processes (DSC) in fullerene bromo- and bromochloroderivatives.

\begin{tabular}{llllrl}
\hline Sample & Thermal process & $\begin{array}{l}\text { Temperature range } \\
\left({ }^{\circ} \mathrm{C}\right)\end{array}$ & $\begin{array}{l}\Delta \mathrm{H} \\
(\mathrm{kJ} / \mathrm{kg})\end{array}$ & $\begin{array}{l}\mathrm{H}_{\mathrm{n}} \\
(\mathrm{mW})\end{array}$ & $\begin{array}{l}\text { Total thermal } \\
\text { change } \Delta \mathrm{H}(\mathrm{kJ} / \mathrm{kg})\end{array}$ \\
\hline $\mathrm{C}_{60} \mathrm{Br}_{14}$ & No. & $122.2-195.1$ & -326.8 & 16.8 & $3,906.2$ \\
bromoderivative & 1 & $418.1-504.2$ & 4233.0 & 306.7 & \\
& 2 & $152.4-199.8$ & -297.1 & 24.2 & $2,270.6$ \\
$\mathrm{C}_{60} \mathrm{Br}_{10} \mathrm{Cl}_{4}$ & 1 & $390.0-449.0$ & 2084.0 & 335.5 & 24.9 \\
bromochloroderivative & 2 & $449.0-490.5$ & 437.2 & 9.4 & \\
\hline
\end{tabular}

$\Delta H$ : Total thermal change during the process according to DSC curves $(\Delta \mathrm{H}>0$, exothermic process, $\Delta \mathrm{H}<0$, endothermic proess $) ;$ $H_{n}$ : Peak height of the thermal process on the DSC curve in the absolute value related to the point which represents the beginning of the thermal process.

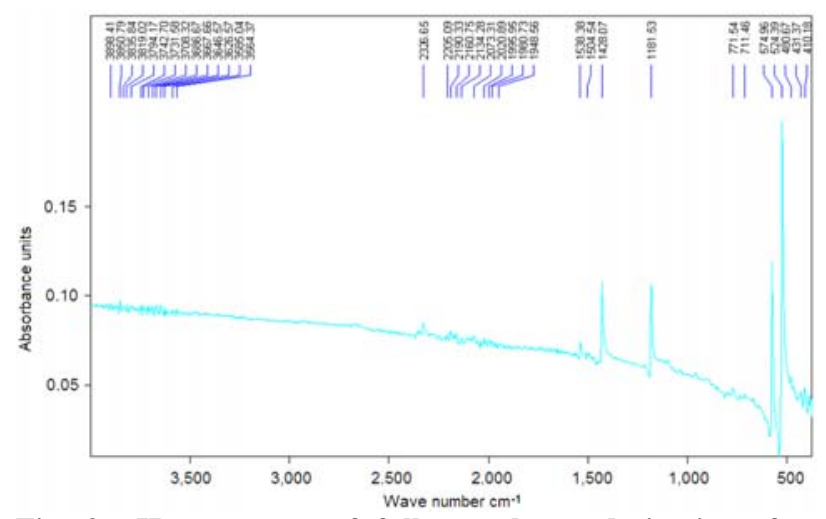

Fig. 9 IR spectrum of fullerene bromoderivative after heating to $250{ }^{\circ} \mathrm{C}$.

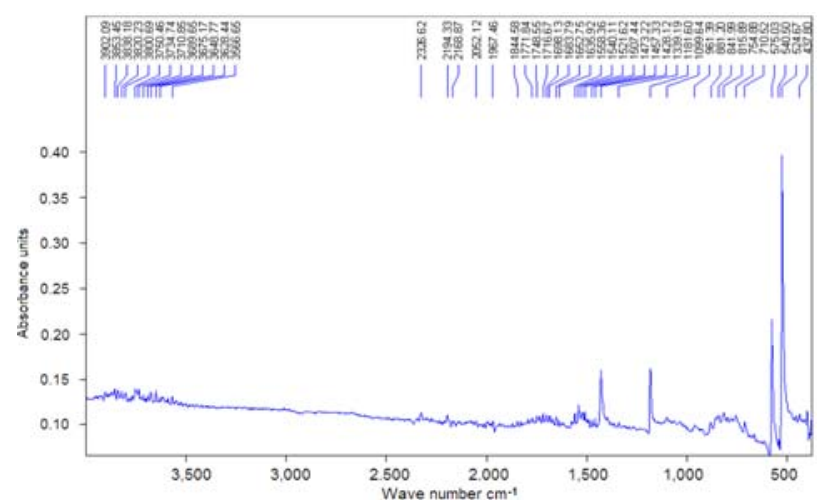

Fig. 10 IR spectrum of fullerene bromochloroderivative after heating to $250{ }^{\circ} \mathrm{C}$.

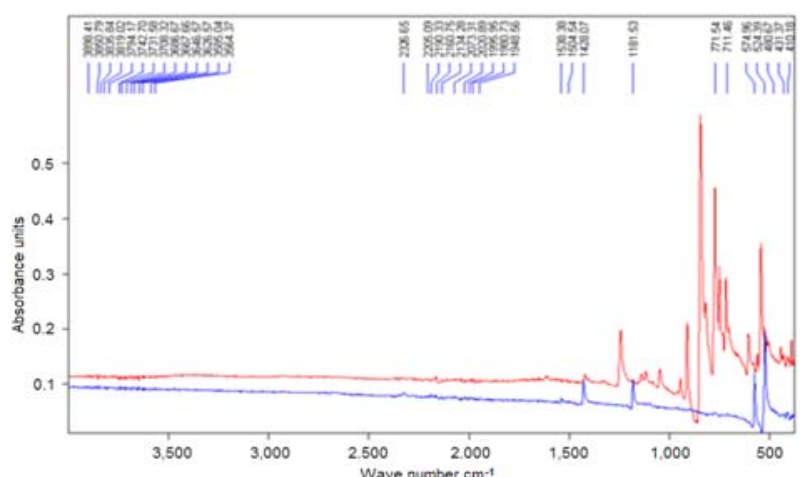

Fig. 11 Comparison of IR spectrums of the initial fullerene bromoderivative (upper spectrum) and of the same substance after its heating to $250{ }^{\circ} \mathrm{C}$ (lower spectrum).

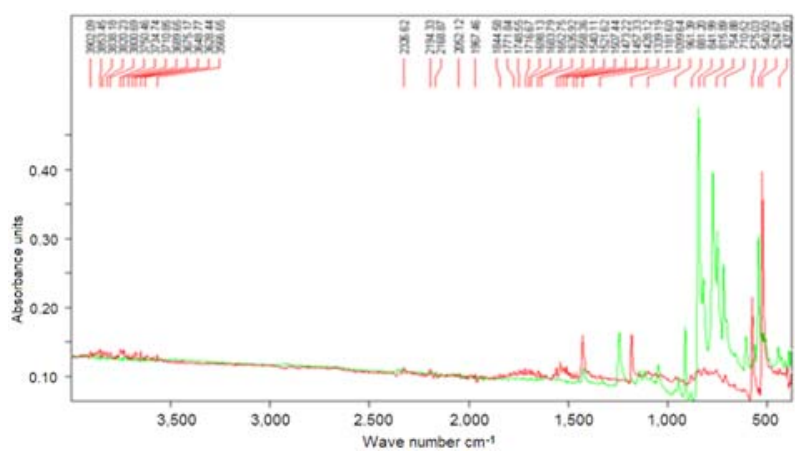

Fig. 12 Comparison of IR spectrums of the initial fullerene bromochloroderivative (upper spectrum) and of the same substance after its heating to $250^{\circ} \mathrm{C}$ ( lower spectrum). 


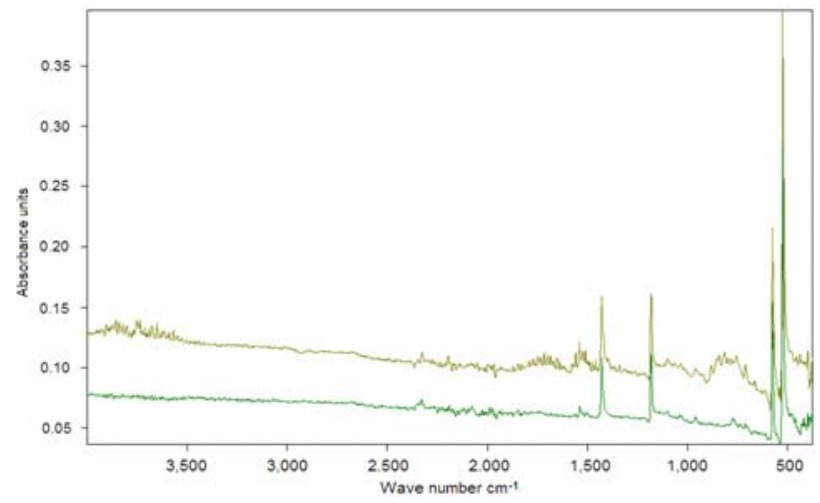

Fig. 13 Comparison of IR spectrums of the derivatives after the heating to $250{ }^{\circ} \mathrm{C}$ (upper spectrum, bromochloroderivative; lower spectrum, bromoderivative).

The results indicate that in case of thermal stress of the bromoderivative beyond the temperature of its endoeffect, i.e., after a probable release of bromine, we obtained an IR spectrum practically identical with that of the initial fullerene (compare Figs. 6 and Fig. 11).

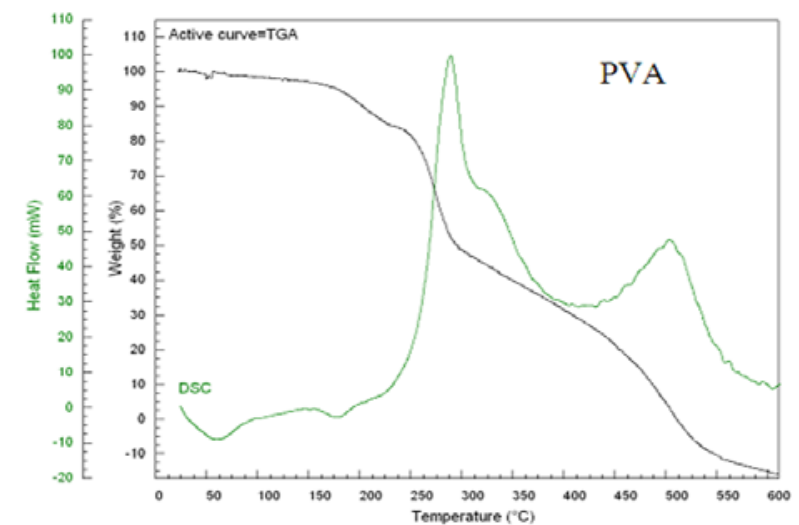

(a)

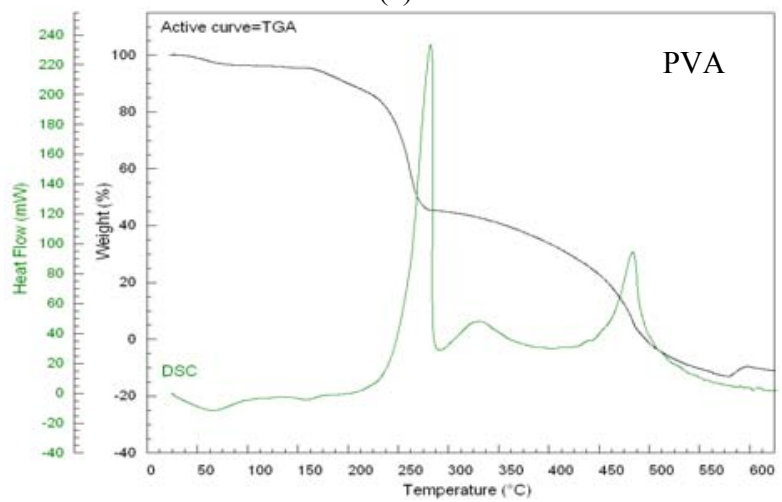

(c)
A different result was found for bromochloroderivative sample exposed to thermal stress, where in the interval $861-710 \mathrm{~cm}^{-1}$, the wave numbers (peaks) are characteristic for $\mathrm{C}-\mathrm{Cl}$ bonds.

Meanwhile, the spectrum makes it possible to identify vibration of groups typical for oxidation products of carbon, such as $\mathrm{C}=\mathrm{O}$ ca. $1,683 \mathrm{~cm}^{-1}$ (1,683-1,636 cm $\left.\mathrm{cm}^{-1}\right),-\mathrm{C}-\mathrm{O}$ ca. $3,700-3,750 \mathrm{~cm}^{-1}$ and skeleton $-\mathrm{C}-\mathrm{C}=\mathrm{C} 1,556 \mathrm{~cm}^{-1}$. Peaks characterizing vibration of the $\mathrm{C}-\mathrm{Br}$ bond were not identified in either case. Therefore we can conclude that all bromine was released before reaching $250{ }^{\circ} \mathrm{C}$, probably by a radical mechanism. One can also assume that the pentadiene circle radical was probably stabilized with chlorine atoms, which enabled its reaction with atmospheric oxygen and formation of carbonyl or carboxyl groups on a chlorinated $\mathrm{C}_{60}$ molecule.

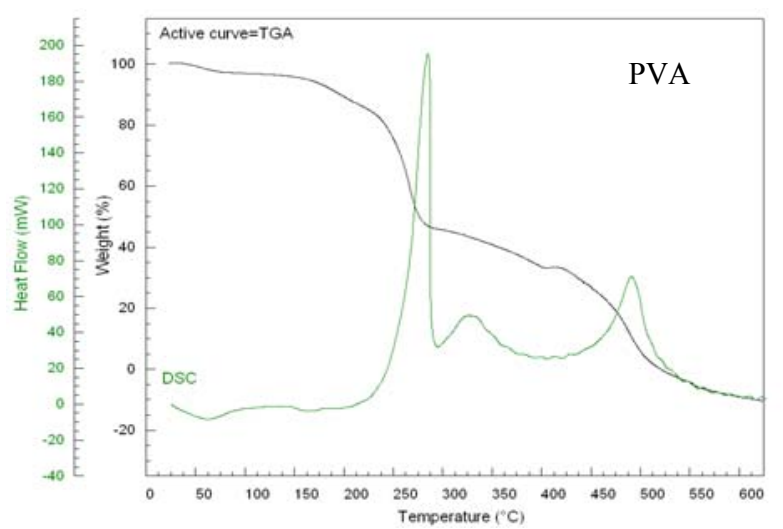

(b)

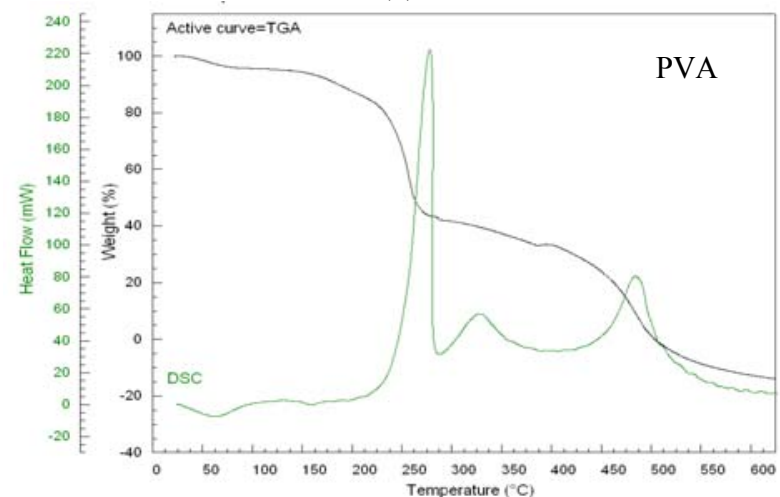

(d)

Fig. 14 Thermal analysis of PVA nanofibers without and with fullerene bromochloroderivative composite in the order: (a) PVA, blank; (b) PVA, 1 wt.\% of bromochloroderivative, (c) PVA, 2 wt.\% of bromochloroderivative, (d) PVA, 3 wt.\% of bromochloroderivative; degradation medium, air, air flow rate $20 \mathrm{~mL} / \mathrm{min}$, temperature regime from 25 to $600{ }^{\circ} \mathrm{C}$, heating rate $10^{\circ} \mathrm{C} / 1 \mathrm{~min}$, weighted quantity $6.4 \mathrm{mg}$. 
Table 6 Division of the TGA curve into temperature intervals.

\begin{tabular}{|c|c|c|c|}
\hline Sample No. & Interval No. & Temperature range $\left({ }^{\circ} \mathrm{C}\right)$ & Weight loss (\%) \\
\hline \multirow{6}{*}{$\begin{array}{l}1 \\
\text { PVA-1\% } \\
\text { bromochloroderivative }\end{array}$} & 1 & $25.0-67.3$ & 2.1 \\
\hline & 2 & $67.3-158.7$ & 2.6 \\
\hline & 3 & $158.7-230.2$ & 10.6 \\
\hline & 4 & $230.2-282.5$ & 36.0 \\
\hline & 5 & $282.5-418.4$ & 13.4 \\
\hline & 6 & 418.4-518.5 & 32.6 \\
\hline \multirow{6}{*}{$\begin{array}{l}2 \\
\text { PVA-2\% } \\
\text { bromochloroderivative }\end{array}$} & 1 & $25-75.7$ & 3.1 \\
\hline & 2 & $75.7-168.9$ & 2.1 \\
\hline & 3 & $168.9-228.8$ & 9.6 \\
\hline & 4 & $228.8-277.0$ & 38.6 \\
\hline & 5 & $277.0-435.5$ & 18.5 \\
\hline & 6 & $435.5-512.3$ & 31.7 \\
\hline \multirow{6}{*}{$\begin{array}{l}3 \\
\text { PVA-3\% } \\
\text { bromochloroderivative }\end{array}$} & 1 & $25.0-72.3$ & 3.6 \\
\hline & 2 & $72.3-153.5$ & 1.9 \\
\hline & 3 & $153.5-226.2$ & 11.1 \\
\hline & 4 & $226.2-276.6$ & 37.9 \\
\hline & 5 & $276.6-402.0$ & 11.6 \\
\hline & 6 & $402.0-532.3$ & 39.5 \\
\hline \multirow{6}{*}{$\begin{array}{l}4 \\
\text { PVA-1\% } \\
\text { bromoderivative }\end{array}$} & 1 & $25.0-64.8$ & 2.3 \\
\hline & 2 & $64.8-163.5$ & 2.9 \\
\hline & 3 & $163.5-231.2$ & 11.4 \\
\hline & 4 & $231.2-287.8$ & 33.0 \\
\hline & 5 & $287.8-475.9$ & 32.4 \\
\hline & 6 & $475.9-557.3$ & 23.7 \\
\hline \multirow{6}{*}{$\begin{array}{l}5 \\
\text { PVA-2\% } \\
\text { bromoderivative }\end{array}$} & 1 & $25.0-75.9$ & 3.0 \\
\hline & 2 & $75.9-157.2$ & 1.9 \\
\hline & 3 & $157.2-223.1$ & 10.8 \\
\hline & 4 & $223.1-282.6$ & 31.3 \\
\hline & 5 & $282.6-395.5$ & 14.6 \\
\hline & 6 & $395.5-547.5$ & 42.6 \\
\hline \multirow{6}{*}{$\begin{array}{l}6 \\
\text { PVA-3\% } \\
\text { bromoderivative }\end{array}$} & 1 & $25.0-76.0$ & 3.2 \\
\hline & 2 & $76.0-152.2$ & 1.9 \\
\hline & 3 & $152.2-213.6$ & 7.9 \\
\hline & 4 & $213.6-277.6$ & 32.0 \\
\hline & 5 & $277.6-472.1$ & 32.3 \\
\hline & 6 & $472.1-537.3$ & 24.8 \\
\hline
\end{tabular}

Interpretation of results of thermal tests of the prepared PVA nanofibers, fullerene bromochloro- and bromoderivatives is that:

Visible differences in the course of thermal decomposition of PVA nanofibers with composites made of fullerene bromochloro- and bromoderivatives are shown in the measured TGA and DSC curves, (Figs. 14 and 15 and Tables 6 and 7).
PVA nanofibers with fullerene bromochloroderivative undergo

decomposition in the air with three exothermic effects while bromoderivative demonstrates two exothermic effects, even through the first one is partly non-formed.

The total thermal change of the decomposition of nanofibers with bromochloroderivative is essentially the same (Table 7 , range $1 \%$ of the value) regardless of the weight content of the composites, within $1 \%-3 \%$ it is lower than in case of bromoderivative. For bromoderivatives one can idenfity a certain 
dependence of a decline (cca. by $10 \%$ ) of the total thermal change on the content of bromoderivative in nanofibres, see the $\Delta H$ values in Table 7 . The decline of $\Delta H$ corresponds always to ca. $10 \%$ when the composite concentration changes by $1 \%$.

\section{Discussion}

There are a number of publications dealing with halogen derivatives of fullerenes [9-16] that describe preparation and identification of bromo- and chloroderivatives of fullerene $\mathrm{C}_{60}$. The content of bromine in $\mathrm{C}_{60} \mathrm{Br}_{\mathrm{n}}$ has been defined in the range $2<\mathrm{n}$ $<24$, depending on reaction conditions (direct contact with bromine, reaction in a solvent, reaction time and temperature etc.), a higher content of bromine than $\mathrm{n}=$ 24 is ascribed to an adduct with bromine and

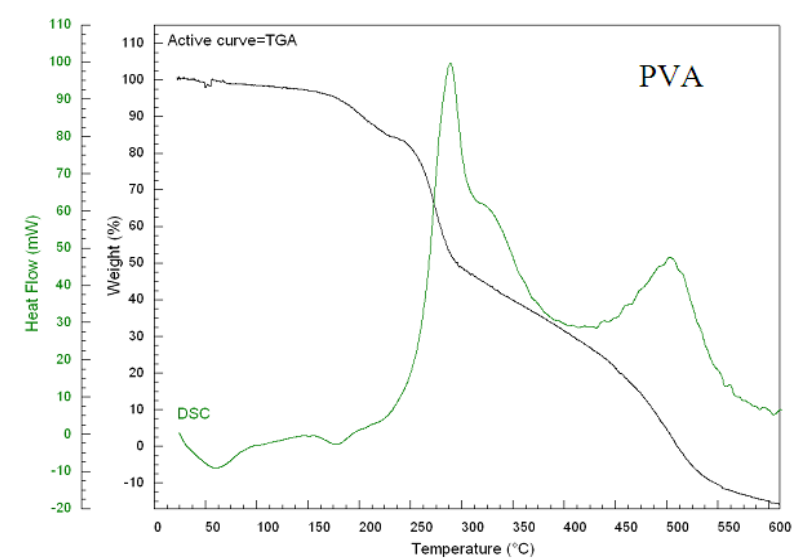

(a)

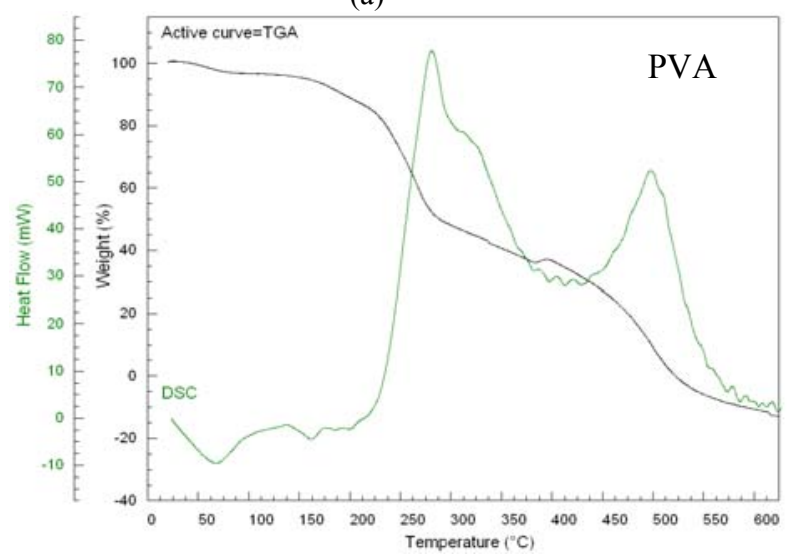

(c)

Fig. 15 Thermal analysis of PVA without and with fullerene bromoderivative composite in the order: (a) PVA, blank, (b) PVA, 1 wt. $\%$ of bromochloroderivative, (c) PVA, 2 wt.\% of bromochloroderivative, PVA, (d) 3 wt.\% of bromochloroderivative; degradation medium, air, air flow rate $20 \mathrm{~mL} / \mathrm{min}$, temperature regime from $25-600{ }^{\circ} \mathrm{C}$, heating rate $10{ }^{\circ} \mathrm{C} / \mathrm{min}$, weighted quantity $6.4 \mathrm{mg}$. bromination in solvents may also produce adducts with a solvent, e.g., $\mathrm{CS}_{2}, \mathrm{CHBr}_{3}, \mathrm{C}_{6} \mathrm{H}_{4} \mathrm{Cl}_{2}$, etc..

The most frequently used methods for identification of the prepared products included:

Elemental analysis, IR spectroscopy, X-ray analysis, TGA analysis. Identical IR spectrums were measured both for the bromoderivative and bromochloroderivative: $1,242 \mathrm{w}, 911 \mathrm{w}, 844$ vs, 773 vs, $749 \mathrm{~m}, 718 \mathrm{~m}$ and $543 \mathrm{~m}\left(\mathrm{~cm}^{-1}\right)$.

Only the most prominent peaks (vs) are indicated below for the published spectrums:

$\mathrm{C}_{60} \mathrm{Br}_{24}: 851 \mathrm{~cm}^{-1}[10] ; \mathrm{C}_{60} \mathrm{Br}_{8}: 849 \mathrm{~cm}^{-1}[10]$; $\mathrm{C}_{60} \mathrm{Br}_{8}: 847 \mathrm{~cm}^{-1}$ [11]; $\mathrm{C}_{60} \mathrm{Br}_{24}: 849 \mathrm{~cm}^{-1}$ [11]; $\mathrm{C}_{60} \mathrm{Br}_{14}: 842 \mathrm{~cm}^{-1}$ [11]; $\mathrm{C}_{60} \mathrm{Br}_{8} \cdot 2 \mathrm{Br}_{2}: 720 \mathrm{~cm}^{-1}, 846$ $\mathrm{cm}^{-1}$ [11]; $\mathrm{C}_{60} \mathrm{Br}_{14} \cdot \mathrm{Br}_{2}: 842 \mathrm{~cm}^{-1}$ [12]; $\mathrm{C}_{60} \mathrm{Br}_{24} \cdot 2 \mathrm{Br}_{2}$ : $846 \mathrm{~cm}^{-1}$ [12].

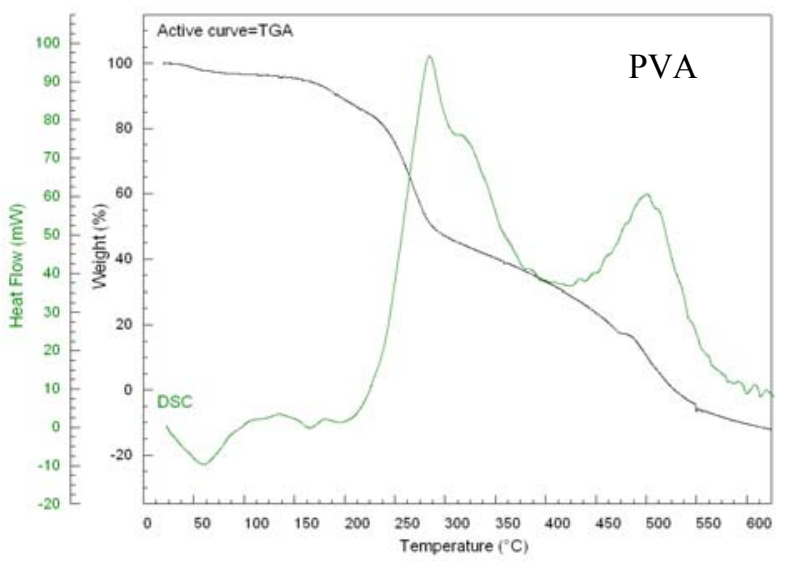

(b)

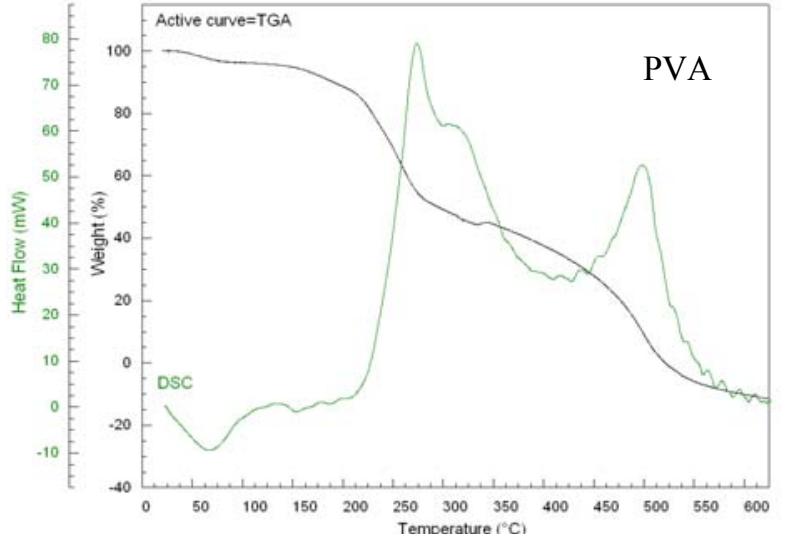

(d) 
Table 7 Parameters of the ongoing thermal processes (DSC).

\begin{tabular}{|c|c|c|c|c|}
\hline Sample No. & Temperature range $\left({ }^{\circ} \mathrm{C}\right)$ & $\Delta \mathrm{H}(\mathrm{kJ} / \mathrm{kg})$ & $\mathrm{H}_{\mathrm{fl}}(\mathrm{mW})$ & Total thermal energy change $\Delta \mathrm{H}(\mathrm{kJ} / \mathrm{kg})$ \\
\hline \multirow{4}{*}{$\begin{array}{l}1 \\
\text { PVA-1\% } \\
\text { bromochloroderivative }\end{array}$} & $25.0-97.7$ & -404.9 & 5.7 & \multirow{4}{*}{$4,273.2$} \\
\hline & $218.3-290.7$ & $2,402.6$ & 192.6 & \\
\hline & $290.7-378.5$ & 630.9 & 21.5 & \\
\hline & $432.3-544.2$ & $1,644.6$ & 43.2 & \\
\hline \multirow{4}{*}{$\begin{array}{l}2 \\
\text { PVA-2\% } \\
\text { bromochloroderivative }\end{array}$} & $25.0-105.3$ & -520.1 & 7.7 & \multirow{4}{*}{$4,279.0$} \\
\hline & 204.1-289.9 & $2,671.5$ & 232.3 & \\
\hline & 289.9-372.4 & 517.7 & 18.7 & \\
\hline & $433.7-541.5$ & $1,609.9$ & 59.9 & \\
\hline \multirow{4}{*}{$\begin{array}{l}3 \\
\text { PVA-3\% } \\
\text { bromochloroderivative }\end{array}$} & $25.0-100.4$ & -361.7 & 7.1 & \multirow{4}{*}{$4,338.9$} \\
\hline & $211.7-284.5$ & $2,527.4$ & 216.9 & \\
\hline & 285.9-369.7 & 639.6 & 25.1 & \\
\hline & $424.8-530.5$ & $1,533.6$ & 44.9 & \\
\hline \multirow{3}{*}{$\begin{array}{l}4 \\
\text { PVA-1\% } \\
\text { bromoderivative }\end{array}$} & $25.0-106.5$ & -492.2 & 11.7 & \multirow{3}{*}{$5,679.9$} \\
\hline & $199.5-414.5$ & 4353.8 & 94.8 & \\
\hline & $414.5-581.9$ & 1817.3 & 23.3 & \\
\hline \multirow{3}{*}{$\begin{array}{l}5 \\
\text { PVA-2\% } \\
\text { bromoderivative }\end{array}$} & $25.0-110.3$ & -471.3 & 6.9 & \multirow{3}{*}{$5,138.3$} \\
\hline & $200.6-393.8$ & $3,939.9$ & 79.7 & \\
\hline & $429.0-574.1$ & $1,669.7$ & 23.9 & \\
\hline \multirow{3}{*}{$\begin{array}{l}6 \\
\text { PVA-3\% } \\
\text { bromoderivative }\end{array}$} & $25.0-124.2$ & -532.5 & 9.3 & \multirow{3}{*}{$4,521.2$} \\
\hline & $203.2-394.8$ & $3,764.9$ & 77.1 & \\
\hline & $441.4-555.5$ & $1,288.8$ & 23.5 & \\
\hline
\end{tabular}

$\overline{\Delta H}$ : thermal energy change accompanying the process based on DSC curves $(\Delta \mathrm{H}>0$, exothermic process , $\Delta \mathrm{H}<0$, endothermic process);

$H_{f l}$ : height of the peak of the thermal process on the DSC curve in the absolute value related to the point which represents the beginning of the thermal process.

The following data have been published about the thermal stability of the prepared products: $\mathrm{C}_{60} \mathrm{Br}_{24}$ : two levels of decomposition at $45^{\circ} \mathrm{C}$ and $170{ }^{\circ} \mathrm{C}$ [12]. $\mathrm{C}_{60} \mathrm{Br}_{24}$ : beginning of decomposition at $100{ }^{\circ} \mathrm{C}$, maximum at $162{ }^{\circ} \mathrm{C}[13,14] \mathrm{C}_{60} \mathrm{Br}_{24}$ : at $90{ }^{\circ} \mathrm{C}[10]$ $\mathrm{C}_{60} \mathrm{Br}_{8}$ : beginning of decomposition at $70{ }^{\circ} \mathrm{C}$ [10] Pressure of developing gases was measured during decomposition of $\mathrm{C}_{60} \mathrm{Br}_{6}$ [13] and based on the obtained values the authors anticipated gradual decomposition with partial maximums at $138{ }^{\circ} \mathrm{C}, 175$ ${ }^{\circ} \mathrm{C}$ and $204{ }^{\circ} \mathrm{C}$, while one atom of bromine releases from cyclopentane circle in the temperature interval 90-187 ${ }^{\circ} \mathrm{C}$ and cyclopentadienyl radical operates as a intermediary product of decomposition, followed by release of the remaining five bromine atoms. The authors anticipate a similar course of decomposition also for $\mathrm{C}_{60} \mathrm{Br}_{24}$.

The shapes of DSC curves of our products in the endo effect area are different. It is the area where we anticipate release of bromine. For bromoderivative the range is $62{ }^{\circ} \mathrm{C}\left(126-188^{\circ} \mathrm{C}\right)$, the shape of the DSC curve is softer (Fig. 7), potentially hiding partial maximums, which may reflect gradual release of bromine through intermediate products of decomposition, e.g., $\quad \mathrm{C}_{60} \mathrm{Br}_{8}$. For bromochloroderivative the range is smaller, $40{ }^{\circ} \mathrm{C}$ $\left(152-192{ }^{\circ} \mathrm{C}\right)$ with a positive maximum on the DSC curve (Fig. 8). In respect to the composition of our bromoderivative $\mathrm{C}_{60} \mathrm{Br}_{14}$, the publication [12] states that the substance with this ratio of fullerene and bromine is an intermediate product before obtaining the final product $\mathrm{C}_{60} \mathrm{Br}_{24}$. 
Programs MOPAC/AM1 [12] were used to calculate $\Delta H$ values and two stable isomers were proposed for $14 \mathrm{Br}$, including their structure in form of a Schlegel diagram. A certain difference between our results and their derivative was that they prepared their derivative during $30 \mathrm{~min}$ of contact between fullerene and bromine and after $10 \mathrm{~h}$ they obtained their product $\mathrm{C}_{60} \mathrm{Br}_{24}$.

The contact to prepare our product lasted $72 \mathrm{~h}$ in total. One year later the essentially same authors [11] described an experiment in which they extended the contact time of fullerene and bromine to 1-2 $\mathrm{d}$. The reaction product, adduct $\mathrm{C}_{60} \mathrm{Br}_{14} \cdot \mathrm{Br}_{2}$, subsequently spontaneously decomposed to $\mathrm{C}_{60} \mathrm{Br}_{14}$ and bromine and its thermal decomposition occurred in one stage.

Fullerene chloroderivatives can not be prepared by a direct reaction of gaseous or liquid chlorine and fullerene $\mathrm{C}_{60}$. It can be synthesized by means of chlorination reagents, e.g., $\mathrm{SbCl}_{5}, \mathrm{VCl}_{4}, \mathrm{KICl}_{4}, \mathrm{VOCl}_{3}$, $\mathrm{ICl}$ at temperatures $200-300{ }^{\circ} \mathrm{C}$ using relatively long reaction times (days).

Derivatives $\mathrm{C}_{60} \mathrm{Cl}_{n}$ have been described, where $n=$ $6,8,10,12,26$ and 30 [14]. The least stable derivative $\mathrm{C}_{60} \mathrm{Cl}_{6}$ (prepared by reaction of fullerene with $\mathrm{ICl}$ in benzene) may be used for a direct reaction with bromine to prepare $\mathrm{C}_{60} \mathrm{Br}_{24}$ [16]. The same reaction in case of more stable fullerene chloroderivatives, such as $\mathrm{C}_{60} \mathrm{Cl}_{n}$, where $n=8,12,14$, results with a very low degree of conversion even after a long reaction time.

Fullerene bromoderivative $\mathrm{C}_{60} \mathrm{Br}_{24}$ has been successfully chlorinated with $\mathrm{SbC}_{15}$ at $140{ }^{\circ} \mathrm{C}$ for $14 \mathrm{~d}$ with $\mathrm{KICl}_{4}$ at $150{ }^{\circ} \mathrm{C}$ for $90 \mathrm{~d}$. The prepared $\mathrm{C}_{60} \mathrm{Cl}_{24}$ has the same tetrahedral structure as the initial $\mathrm{C}_{60} \mathrm{Br}_{24}$.

Fullerene chloroderivatives are thermally more stable than bromoderivatives and they decompose to chlorine and fullerene. $\mathrm{C}_{60} \mathrm{Clr}_{24}$ decomposes thermally at $280-390{ }^{\circ} \mathrm{C}$ and $\mathrm{C}_{60} \mathrm{Clr}_{30}$ decomposes at $400-550{ }^{\circ} \mathrm{C}$. The latter thermally stable substance has a "drum" structure, i.e., the spherical molecule of the original fullerene is flattened. The strongest peaks in the IR spectrum are at $775,822,854,895,903,918 \mathrm{~cm}^{-1}$. The search for information has shown that it is possible to brominate a partly chlorinated (non-stable) fullerene $\mathrm{C}_{60} \mathrm{Cl}_{6}$ with elemental bromine when using long reaction times or, on the other hand, to chlorinate bromoderivatives with $\mathrm{SbCl}_{5}$ or $\mathrm{KIC}_{14}$ at a relatively high temperature $[14,16]$. In our opinion, the temperature used for chlorination $\left(140{ }^{\circ} \mathrm{C}\right)$ is above the decomposition temperature of the bromoderivative so the probable mechanism is chlorination of activated fullerene molecule after the bromine is released and the bromine is trapped by 5-valent antimony.

The comparison of the prepared halogen derivatives of fullerene with literary data has confirmed that the resulting halogen content depends on reaction conditions. Results depend on whether the reaction occurs directly in a solution, on reaction temperature, reaction time and also on the halogenating agent.

We have demonstrated experimentally that a retarder on $\mathrm{C}_{60}$ oxi basis has good results in increasing of thermal resistance of PVA-based nanofibers. The optimum concentration in the nanofiber is cca. $2 \mathrm{wt} . \%$. However, a further increase of its content above $3 \%$ has a negative effect on thermal stability of nanofibers. A similar result indicating that an additional increase of composite weight in polymer deteriorates its thermal resistance was published, e.g., for polypropylene with added MWNT [4].

Based on the functional groups bonded to fullerene molecules in $\mathrm{C}_{60} \mathrm{Oxi}$ (the IR spectrum in Fig. 3), we can expect reactions with $-\mathrm{OH}$ groups on PVA by acetilization, esterification or formation of hydrogen bonds between $-\mathrm{OH}$ groups of polymers and $\mathrm{C}_{60}$ oxi.

Higher concentrations of $\mathrm{C}_{60} \mathrm{Oxi}$ probably affect chemical properties of the polymer which may have an impact on deteriorating stability of nanofibers. Organic bromoderivatives in general are often successfully used as fire retarders and therefore we hoped to apply our fullerene bromoderivative to achieve a significant thermal resistance of nanofibers. The explanation can be found in preparation of the 
initial polymer, during its cross-linking which is performed for $4 \mathrm{~min}$ at $135^{\circ} \mathrm{C}$. During this process we observed yellowing of the initial material. The temperature of cross-linking was close to the temperature at which the bromoderivative has been demonstrated to decompose and to release bromine, see the TGA and DSC curves and Fig. 7. This means that the composite was in this case probably a debrominated fullerene whose retarder effect slightly increased with its increasing content in the fiber. The bromochloroderivative changed the course of thermal decomposition of nanofibers and the total thermal energy change of the decomposition was approximately same as for nanofibers prepared from composite $\mathrm{C}_{60} \mathrm{Oxi}$ containing $1 \mathrm{wt} . \%$.

\section{Conclusions}

Oxidation of fullerene with peracetic acid was used to produce $\mathrm{C}_{60} \mathrm{Oxi}$, the so-called oxoderivative, which is partly soluble in water and numerous experiments have demonstrated its radioprotective properties $[7,8,17]$. Earlier in published work [7, 18] we demonstrated its sufficient solubility in water and low toxicity to the sensitive organism Danio rerio and its radioprotective effect which led to increasing in $\mathrm{D}_{50}$ (in Gy) of about $100 \%$. It has been demonstrated that the substance is able to eliminate superoxide radicals, $\mathrm{OH}$ radicals and other oxidizing agents that attack lipids, proteins, PVA and other macromolecules.

Oxoderivative fullerene preparation for the purpose of the ionizing radiation protection resulted in the preparation of material with ability to recapture free radicals has inspired to retardation experiments with combustion, which is also the radical process. Demonstration of decreased fire activity of aerosol with $\mathrm{C}_{60}$ oxi [19] confirmed that there was prepared highly active "free radical scavenger" and it opens many perspectives for research into its use in the protection and safety of persons related effects and chemical aggressiveness of reactive radical forms.
Testing the possibility of using halogen- and oxoderivatives of $\mathrm{C}_{60}$ in nanofibres as nanocomposites using thermogravimetric analysis demonstrated the inhibitory effect in the thermo-oxidative degradation of the prepared nanowires. It opens up possibilities for further study of thermal properties of these materials, which can be applied in the area of the security and fire protection.

\section{References}

[1] T. Kashiwagi, A.B. Morgan, J.M. Antonucci, M.R. Vanlandingham, R.H. Harris, W.H. Awad, et al., Thermal and flammability properties of a silicapoly (methylmethacrylata) nanocomposite. J. Appl. Sci. 89 (2003) 2072-2078.

[2] A. Laachachi, E. Leroy, M. Cochez, M. Ferriol, J.M.L. Cuesta, Use of oxide nanoparticles and organoclay to improve thermal stability and fire retardancy of poly (methyl methacrylate), Polym. Degrad. Stable 89 (2005) 344-352.

[3] T. Kashiwagi, K.I. Winey, K.M. Groth, J. Shields, S.P. Bellayer, H. Kim, et al., Flammability properties of polymer nanocomposites with single-walled carbon nanotubes: Effects of nanotube dispersion and concentrations, Polymer 46 (2005) 471-481.

[4] T. Kashiwagi, E. Grulke, J. Hilding, K. Groth, R.H. Harris, K. Bulter, et al., Thermal and flammability properties of polypropylene/carbon nanotube nanocomposites, Polymer 45 (2004) 4227-4239.

[5] K. Klouda, V. Witkovská, E. Zemanová, E. Kostakova, O. Dvorak, H. Matheisova, Retarding properties of fullerene $\mathrm{C}_{60}$ and its derivatives, Spectrum 2 (2011) 55-59.

[6] E. Kostakova, E. Zemanova, P. Mikes, J. Soukupova, H. Matheisova, K. Klouda, Electrospinning and electrospraying of polymer solutions with spaerical fullerenes, in: Conference Proceedings Thomson Reuters Nanocon Tanger, 2012, pp. 435-440.

[7] E. Beranová (Zemanová), K. Klouda, L. Vávra, K. Zeman, J. Máchová, J. Zenka, et al., Radioprotective properties and toxicity test of $\mathrm{C}_{60}$ fullerene derivative in vivo \& in vitro, in: Conference Proceedings Thomson Reuters Nanocon, Tanger, Ltd., 2010, pp. 251-262.

[8] E. Zemanová, P. Danihelka, K. Klouda, K. Zeman, C 60 fullerene derivative: radioprotective properties and toxicity test in vivo \& in vitro, Journal of Materials Science and Engineering A 2 (3) (2012) 302-312.

[9] J.B. Peel, R.G. Rothwell, $\mathrm{C}_{60}$ framework response to halogen addition: The stable isomers of $\mathrm{C}_{60} \mathrm{Br}_{2 \mathrm{~m}}$, Aust. J. Chem. 47 (1994) 131-141.

[10] M.R. Resmi, K. Smitha, T. Pradeep, Thermal 
decomposition of $\mathrm{C}_{60} \mathrm{Br}_{24}$ and $\mathrm{C}_{60} \mathrm{Br}_{8}$ : Absence of sequential elimination, Proc. Indian Acad Sci (1997) 109 221-228.

[11] P.A. Troshin, E. Kemnitz, S.I. Troyanov, Characterization of reactions of fullerene $\mathrm{C}_{60}$ with bromine: Crystal structures of bromofullerenes $\mathrm{C}_{60} \mathrm{Br}_{6}$, $\mathrm{C}_{60} \mathrm{Br}_{6} \cdot \mathrm{CS}_{2}, \mathrm{C}_{60} \mathrm{Br}_{8} \cdot \mathrm{CHBr}_{3} \cdot 2 \mathrm{Br}_{2}$, and $\mathrm{C}_{60} \mathrm{Br}_{24} \cdot \mathrm{C}_{6} \mathrm{H}_{4} \mathrm{Cl}_{2} \cdot \mathrm{Br}_{2}$, Russ. Chem. Bull, Inter. ED 53 (2004) 2787-2792.

[12] P.A. Troshin, D. Kolesnikov, A.V. Burtsev, R.N. Lubovskaya, N.I. Denisenko, A.A. Popov, et al., Bromination of 60 fulleren: High-yielo synthesi of $\mathrm{C}_{60} \mathrm{Br}_{\mathrm{x}}$, $(\mathrm{x}=6,8,24)$, fullerenes, Nanotubes and Carbon Nanostructures 111 (2003) 47-60.

[13] S.S. Gayathri, M. Kamruddin, A.K. Tyagi, A. Patnaik, Establishing a kinetic control regime for the decomposition of brominated fullerene derivates: $\mathrm{C}_{60} \mathrm{Br}_{24}$ and $\mathrm{C}_{60} \mathrm{Br}_{6}$, Chem. Phys. Lett. 374 (2003) 33-40.

[14] S.I. Royanov, N.B Shuistova, A. Popov, L.N. Sidorov, Synthesis and structures of $\mathrm{C}_{60}$ fullerene chlorides, Russ. Chem. Bull. Inter. ED 54 (2005) 1656-1666.

[15] P.A. Troshin, R.N. Lyubovskaya, I.N. Ioffe, N.B.
Shustova, E. Kemnitz, S.I. Troyanov, Synthesis and structure of the highly chlorinated [60] fullerene $\mathrm{C}_{60} \mathrm{Cl}_{30}$ with a drum-shaped carbon cage, Angew. Chem. Inf. ED 44 (2005) 234-237.

[16] P.A. Troshin, S.A. Baskakov, Y.U.M. Shulga, R.N. Lyubovska, In the chase of mixed halofullerenes: Remarkable transformation of $\mathrm{C}_{60} \mathrm{Cl}_{\mathrm{n}}(\mathrm{n}=6,8,12,14)$ to $\mathrm{C}_{60} \mathrm{Br}_{24}$, Full. Nanot. Carb. Nanostruct. 12 (2004) 159-163.

[17] E. Zemanova, K. Klouda, K. Zeman, $\mathrm{C}_{60}$ fullerene derivative: influence of nanoparticles size on toxicity and radioprotectivity of water soluble fullerene derivative, Journal of Materials Science and Engineering A1 1 (7) (2011) 948-956.

[18] E. Zemanova, K. Klouda, Preparation of water-soluble fullerene derivative by reaction with peracetic acid and its nanoparticle size distribution, Journal of Materials Science and Engineering A 2 (1) (2012) 86-97.

[19] K. Klouda, E. Beranova (Zemanova), S. Cafourek, The role of fullerene $\mathrm{C}_{60}$ at aerosol firefighting, in: Conference Proceedings Thomson Reuters Nanocon, Tanger, 2009, p. 90. 